\title{
Exercise Testing Three Days After Onset of Acute Myocardial Infarction
}

\author{
ERIC J. TOPOL, MD, JACK E. JUNI, MD, WILLIAM W. O'NEIL, MD, \\ JOHN M. NICKLAS, MD, MICHAEL J. SHEA, MD, KAREN BUREK, BS, RN, \\ and BERTRAM PITT, MD
}

To determine the feasibility and predictive value of early exercise testing 72 hours after acute myocardial infarction, 109 consecutive patients who received reperfusion therapy were prospectively evaluated. In the group studied, in $87(80 \%)$ the course was uncomplicated 3 days after admission, as defined by a lack of congestive heart failure, arrhythmias and angina, and 53 patients $(49 \%)$ performed heart rate-limited ( 140 beats $/ \mathrm{min}$ ) treadmill exercise. These patients exercised for $7.9 \pm 3.4 \mathrm{~min}-$ utes, achieving a heart rate of $129 \pm 11$ beats $/ \mathrm{min}$ and a systolic blood pressure of $151 \pm 27 \mathrm{~mm} \mathrm{Hg}$. The exercise test was not accompanied by any protracted ischemia, infarction or significant arrhyth. mias. Accompanying tomographic thallium-201 scintigraphy demonstrated a reversible perfusion defect in 14 patients $(26 \%)$, no evidence for ischemia in 36 patients $(69 \%)$ and an equivocal result in 3 patients $(6 \%)$. Of the 14 patients with a positive exercise-thallium test result, 4 had an adverse clinical outcome of either reinfarction, postinfarction angina or ventricular tachycardia during hospital days 4 to 10; an adverse in-hospital outcome was not seen in the $\mathbf{4 0}$ patients with a negative exercisethallium test result $(p=0.009)$. Thus, early exercise testing after acute myocardial infarction is safe in selected patients with an uncomplicated course and the test is predictive of in-hospital clinical outcomes.

(Am J Cardiol 1987;60:958-962)
S the first early ( 7 weeks) exercise test after acute myocardial infarction (AMI) reported by Torkelson in $1964,{ }^{1}$ our approach to the patient with AMI has been revamped. In the past 5 years, it has become standard care to perform a low-level exercise treadmill test in suitable patients before hospital discharge approximately 7 to 10 days after admission. ${ }^{2-7}$ Concurrent with this practice, interventional strategies to achieve myocardial reperfusion with thrombolytic agents and mechanical recanalization have become popular.,9 The strategies of thrombolysis and coronary angioplasty incur a significant expense, which is not offset except for

From the Division of Cardiology, Department of Internal Medicine, University of Michigan Medical Center, Ann Arbor, Michigan. This study was sponsored in part by grants from Genentech, Inc., South San Francisco, Californịa, and USCI Division, C.R. Bard, Inc., Billerica, Massachusetts. Manuscript received April 3, 1987; revised manuscript received and accepted June 26, 1987.

Address for reprints: Eric J. Topol, MD, B1-F245 University of Michigan Medical Center, 1500 East Medical Center Drive, Ann Arbor, Michigan 48109-0022. the potential for mortality reduction or improved quality of life. In patients receiving very early reperfusion therapy, limitation of infarct size has been demonstrated $^{10,11}$ and the possibility for earlier mobilization and hospital discharge is suggested. This study determincs the safety, feasibility and predictive value of exercise testing with scintigraphy 3 days after AMI. A secondary objective was to consider whether thrombolysis and angioplasty lead to an increased likelihood for a patient to perform an early exercise test and have a negative result.

\section{Methods}

Patient selection: Between September 1985 and March 1986, 109 consecutive patients with AMI who received reperfusion therapy were admitted to the University of Michigan Hospital. The diagnosis of AMI was determined by the clinical history, elevation in serial creatine kinase isoenzyme levels and typical electrocardiographic changes. All patients with an uncomplicated AMI were asked to participate in this study and informed consent was obtained before exercise testing. The study population consisted of all 
patients who received an acute intervention, including coronary angioplasty with or without thrombolysis, and thrombolytic therapy alone. All patients underwent emergency cardiac catheterization within 6 hours of the onset of symptoms. Patients with transmural as well as non-Q-wave AMI were included. Approval to conduct the study was granted by the institutional review board. The protocol design is shown in Figure 1.

An uncomplicated AMI was defined as the absence of the following criteria at 3 days after admission: (1] postinfarction angina defined as rest pain lasting more than 20 minutes associated with electrocardiographic changes; (2) congestive heart failure, diagnosed by a new requirement for digoxin and furosemide therapy or bibasilar rales half way up the posterior lung fields, or a ventricular gallop; (3) left ventricular ejection fraction less than $35 \%$ as determined by left ventriculography or radionuclide angiography; (4) systolic blood pressure less than $90 \mathrm{~mm} \mathrm{Hg}$; (5) higher than Lown class 3 ventricular arrhythmia ${ }^{12}$; and (6) highgrade (Mobitz II or third-degree) atrioventricular block.

Exercise testing: On the morning of the fourth hospital day, patients were brought to the exercise laboratory where a treadmill exercise test with accompanying 12-lead electrocardiography and tomographic thallium scintigraphy was performed. ${ }^{13}$ The exercise treadmill protocol was: stage $1-2 \mathrm{mph}, 10 \%$ grade for 3 minutes; stage $2-3.0 \mathrm{mph}$ at $12 \%$ grade for $3 \mathrm{~min}$ utes; stage 3-3.0 mph at $14 \%$ grade for 3 minutes; stage $4-3.0 \mathrm{mph}$ at $16 \%$ grade for 3.0 minutes; stage $5-3.0 \mathrm{mph}$ at $18 \%$ grade for 3.0 minutes; and, if necessary, stage $6-3.0 \mathrm{mph}$ at $20 \%$ grade for 3 minutes. The workload was increased by 1 stage at the end of each 3minute perod until attainment of an arbitrary target heart rate of 140 beats $/ \mathrm{min}$ or development of clinical symptoms: angina (with accompanying electrocardiographic changes), significant dyspnea, decrease in systolic blood pressure of more than $15 \mathrm{~mm} \mathrm{Hg}$ below the peak value achieved in the prior stage, ventricular tachycardia or inability to walk due to claudication or generalized fatigue. One minute before terminating exercise, $3 \mathrm{mCi}$ of intravenous thallium-201 was administered. Patients underwent tomographic thallium imaging immediately after termination of exercise. A redistribution set of images was acquired 3 to 4 hours later.

A positive exercise response was defined as (1) provocation of angina; (2) horizontal or downsloping ST-segment depression of at least $2.0 \mathrm{~mm}$ below the baseline; or (3) a definite reversible perfusion abnormality as detected by tomographic thallium imaging. Thallium scintigraphy was used in conjunction with the exercise treadmill because of the significant persistent electrocardiographic ST- and T-wave abnormalities present in most of these patients. $\Lambda$ reversible perfusion abnormality resulted in a positive reading of the test whether or not it occurred in the peri-infarct zone. The tomographic thallium studies were interpreted by 2 investigators blinded to the patient's clinical data and the timing of the exercise study (i.e., 4 vs 7
TABLE Demographic Results

\begin{tabular}{lcc}
\hline & $\begin{array}{c}\text { Total Patients } \\
(\mathrm{n}=109)\end{array}$ & $\begin{array}{c}\text { Early ETT Patients } \\
(\mathrm{n}=53)\end{array}$ \\
\hline Age $(\mathrm{yr})$ & $55 \pm 9$ & $51 \pm 7$ \\
Men (\%) & $85(78 \%)$ & $47(89 \%)$ \\
Q-wave AMI (\%) & $96(88 \%)$ & $45(85 \%)$ \\
Anterior (\%) & $42(39 \%)$ & $16(30 \%)$ \\
Inferior (\%) & $61(56 \%)$ & $32(60 \%)$ \\
\hline
\end{tabular}

There were no significant $(p<0.05)$ differences in demographic characteristics in patients performing early ETT compared with the overali study population.

$\mathrm{AMI}=$ acute myocardial infarction; $\mathrm{ETT}=$ exercise treadmill test.

days). $\Lambda$ test was defined as equivocal if there was ambiguity with respect to the presence or absence of a reversible perfusion abnormality. Patients with a negative exercise test result did not have angina, significant ST-segment depression or evidence of a reversible perfusion abnormality. A thallium scan with a fixed defect only was considered negative for the purpose of this study.

Follow-up: The patients were followed for the duration of the hospitalization and for a 6 -month period after leaving the hospital for adverse clinical outcomes. These outcomes included: (1) new onset of angina; (2) reinfarction; (3) congestive heart failure as previously defined; (4) need for coronary artery bypass surgery or percutaneous transluminal coronary angioplasty; (5) ventricular tachycardia or fibrillation; and (6) death. After hospital discharge, follow-up data were obtained by outpatient visit or by telephone contact.

Statistical methods: Values are expressed as mean \pm standard deviation. A Fisher exact test was used to determine the predictive value of a positive exercise test and the differences in uncomplicated infarction rate, ability to perform an early treadmill test, and a negative result of the test between 2 groups of patients: those receiving thrombolytic therapy alone and those who underwent coronary angioplasty with or without thrombolysis.

\section{Results}

Demographics: The relevant demographic characteristics of the overall group of 109 consecutive patients and the subset of 53 patients who underwent early exercise testing are listed in Table I. Fifty-six patients did not undergo exercise testing on day 4 for the following reasons: complicated infarction in 22 (39\%), inability to exercise due to heart failure or debilitated status in $16(29 \%)$, a large inguinal hematoma related to cardiac catheterization and thrombolytic therapy in $9(16 \%)$, noncardiac disease such as severe chronic obstructive pulmonary disease or uncontrolled diabetes in $5(9 \%)$ and refusal to participate in the protocol in $4(7 \%$ ).

The following modes of acute interventional therapy were used in the 109 study patients: intravenous streptokinase (1.5 million units over 30 to 60 minutes) in 10 patients, intravenous tissue-type plasminogen activator ( $150 \mathrm{mg}$ over 6 to 8 hours) in 26 and emergency 
coronary angioplasty (with thrombolysis in 64 pationts or without concurrent thrombolytic treatment in 9 patients) in 73. At exercise testing 3 days after AMI, the 53 patients achieved a heart rate of $129 \pm 11$ beats $/ \mathrm{min}$, systolic blood pressure of $151 \pm 27 \mathrm{~mm} \mathrm{Hg}$ during $7.9 \pm$ 3.4 minutes of the treadmill protocol. The reasons for termination and proportion of patients, respectively, were: target heart rate $(59 \%)$, leg fatigue or claudication $[17 \%)$, fatigue $(13 \%)$, dyspnea $(6 \%)$ and chest pain $(4 \%)$.

Exercise testing: With tomographic thallium scintigraphy, a fixed perfusion defect was identified in 51 of the patients $[96 \%$ ). In 14 patients $(26 \%)$, the test was considered positive because of a reversible perfusion abnormality in 13 patients and angina, $2.5 \mathrm{~mm}$ of STsegment depression, but no reversible thallium defect in 1 patient $(1.8 \%)$. Only 2 of 14 patients (14\%) in this group with reversible perfusion abnormalities had angina and significant ST-segment depression. A negative or equivocal exercise test result occurred in 36 and 3 patients, respectively. No patient had protracted angina, infarction or arrhythmias during or within 24 hours after the exercise test had been performed. The only arrhythmia observed was couplets and frequent ventricular premature beats in 1 patient during the recovery period.

Acute intervention results: Patients who had emergency coronary angioplasty had a similarly high rate of uncomplicated AMI and ability to perform the treadmill test, compared with patients treated with thrombolysis alone $(82 \%$ vs $75 \%, p=0.44$, and $53 \%$ vs $38 \%, p=0.25$, respectively, Figure 3). A trend toward a negative exercise test response was observed in those

Uncomplicated $\mathrm{MI}$ at $72 \mathrm{hrs}$

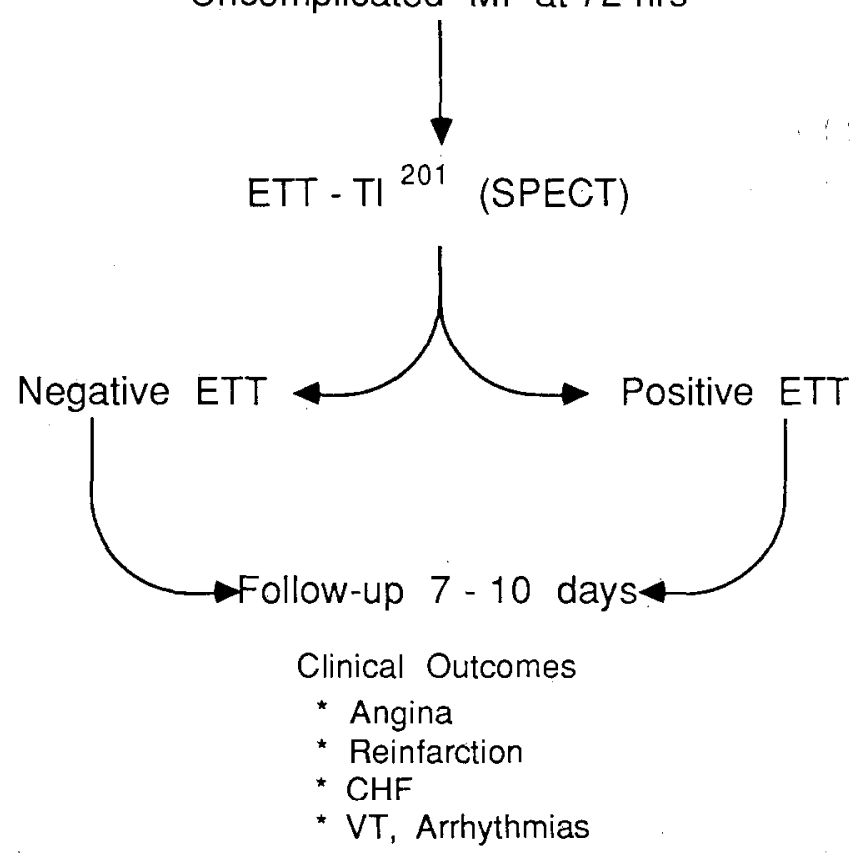

FIGURE 1. Protocol for early exercise testing 72 hours after myocardial infarction. $\mathrm{CHF}=$ congestive heart failure; $\mathrm{ETT}=$ exercise treadmill test; SPECT = single-photon emission computed tomography; $\mathbf{T I}=$ thallium; $\mathbf{V T}=$ ventricular tachycardia. who underwent angioplasty comparcd with those receiving thrombolytic therapy alone $[38 \%$ vs $22 \%$, respectively, $\mathrm{p}=0.15$.

Follow-up: Between the day 4 exercise test and hospital discharge, no adverse clinical event occurred in the 36 patients who had negative responses to the exercise thallium study. These patients were discharged from the hospital at $8 \pm 1$ days. In the group of 14 patients with a positive test, 1 had a reinfarction on day 6,2 had rest angina and 1 patient had both new congestive heart failure and several runs of nonsustained ventricular tachycardia. In the positive exercise test group, hospital discharge was at $13 \pm 3$ days. A significant difference of a positive vs a negative exercise test result for predicting in-hospital clinical outcomes was demonstrated ( 4 of 14 vs 0 of 40 , respectively, $p=0.009$ ). Of the 2 patients in whom angina developed, 1 underwent coronary angioplasty and 1 had coronary artery bypass grafting. In the remaining 12 patients with a positive stress test result, 3 had angioplasty and 1 underwent bypass surgery before leaving the hospital. Thus, the need for a revascularization procedure before hospital discharge was greater among patients with a positive test response $(43 \%)$ than in those with a negative response $(0 \%)$, but the results of the exercise-thallium study influenced decision-making in some patients.

Follow-up data on all 53 patients who underwent early exercise testing has been obtained at $7.1 \pm 0.9$ months after admission to the study. No patient in this group died. In 4 of the patients [11\%) with a negative exercise test response, angina developed. This was secondary to restenosis at a prior angioplasty dilatation site in 2 patients and related to multivessel disease in the other patients. Two patients underwent repeat coronary angioplasty and 2 were referred for bypass sur-

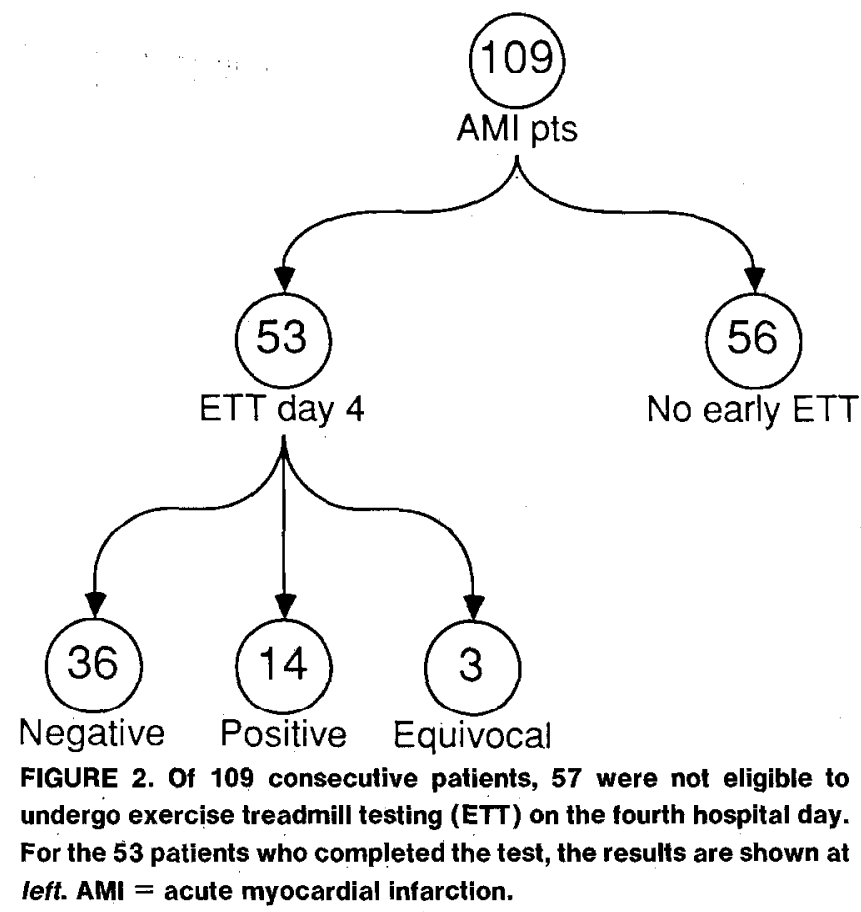


gery. In the group of patients with positive exercise test results, 2 have had angina and have undergone coronary angioplasty. A maximal exercise test was performed in 34 patients at 4 to 6 weeks after hospital discharge. Of the 36 patients with in-hospital negative results, 27 performed a maximal exercise test and 4 patients $(15 \%)$ had provokable ischemia. No patient who underwent early exercise testing had ventricular arrhythmias or a ventricular aneurysm during the follow-up period, as detected by routine Holter monitoring, chest roentgoenogram or 2-dimensional echocardiography.

\section{Discussion}

In this study of pationts with AMI who predominantly received reperfusion therapy, we have demonstrated that a heart rate-limited exercise test is safe and feasible 3 days after admission. Furthermore, the exercise test, performed in conjunction with tomographic thallium scintigraphy, accurately predicted inhospital adverse clinical outcomes.

Previous studies have documented the prognostic value of predischarge or early limited exercise treadmill testing after AMI. ${ }^{2-7}$ However, in these recent studies, the exercise test was administered 7 to 14 days after the infarct, and none of the patients received acute interventional therapy to achieve reperfusion. The aggressive approach of early recanalization of the infarct vessel has been shown to reduce mortality, improve ventricular function, limit infarct size ${ }^{8-11,14}$ but not reduce hospital stay, readmission to the hospital or any other variable associated with cost containment. Thrombolytic therapy alone has been accompanied by a higher rate of postinfarct ischemia and reinfarction than conventional treatment. ${ }^{9,14}$ The present study was not a randomized trial of thrombolysis alone compared with the integrated approach of thrombolysis and mechanical revascularization. Further study is needed to determine whether the combined strategy compared with lytic therapy alone or conventional treatment will lead to a higher proportion of patients whose conditions are uncomplicated, who can perform a very early treadmill test and who have a negative result for inducible ischemia.

The safety of this exercise test 3 days after admission has been supported in the current study by the lack of an adverse outcome during or soon after the test in any of the 53 consecutive patients. Concern about patients exercising soon after AMI has stemmed from the belief that the heart is susceptible to further injury during this period. ${ }^{2}$ No patient in the current study had evidence of ventricular aneurysm formation, extension of the infarction or precipitation of malignant ventricular arrhythmias. Our observation of safety may be limited by type II error, and careful confirmation of these results are important before more widespread use can be recommended.

The exercise test provides an objective assessment of the patient's functional capacity before discharge. It could be argued that the coronary anatomy was defined by emergency angiography in most patients in the current trial, precluding the need for an exercise study. However, in 5 of 14 patients ( $36 \%$ ) with a positive early exercise test response, the infarct vessel had been recanalized with thrombolysis and balloon dilatation with less than a $50 \%$ residual stenosis. On the other hand, in 9 of the 36 patients $(25 \%$ ) with a negative test response, the infarct vessel had a significant residual stenosis ( $70 \%$ or greater) at the end of the emergency catheterization. Thus, early exercise testing provided ancillary data regarding the potential to provoke ischemia that did not accurately reflect the findings of emergency angiography.

A heart rate-limited rather than a symptom-limited test was used in the present study because of the potential to induce an adverse clinical outcome, even though the latter approach has been shown to have a greater prognostic yield when performed at 1 to 2 weeks. ${ }^{2,6}$ In patients who underwent a follow-up maximal exercise test 4 to 6 weeks after the event, the lack of early exercise test sensitivity for detecting ischemia became apparent in $15 \%$ of patients whose test response became positive. An alternative to exercise testing in this very early time frame may be the administration of intravenous dipyridamole with accompanying electrocardiography and thallium scintigraphy, which have been shown to have a high yield in detecting provokable ischemia in the peri-infarct setting. ${ }^{15}$

The safety and predictive value of a negative early treadmill test demonstrate the potential for early hospital discharge 3 days after AMI. Although only onethird of patients in the present study had a negative early exercise test response, this represents a subset with substantial cost-saving potential for reducing the overall length of stay. Recent randomized trials have focused on early vs conventional hospital discharge, ${ }^{16,17}$ and the conventional length of stay after AMI has decreased from 3 weeks to approximately 7 days in the past 10 years. In the current study, patients with uncomplicated AMI and a negative early exercise test result were monitored in the hospital and discharged at $\mathbf{7}$ to $\mathbf{1 0}$ days. Although careful prospective randomized studies are necessary to validate longterm safety and feasibility of this approach, the current results offer promise of selecting a low-risk subset of

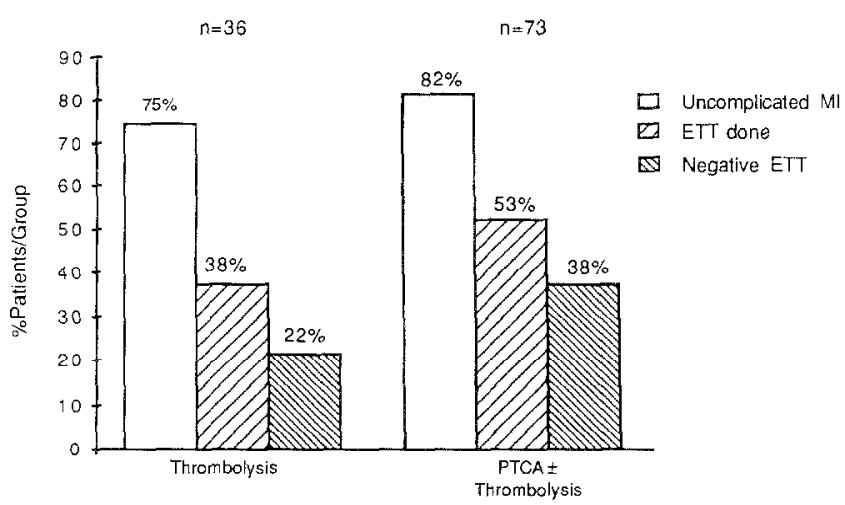

FIGURE 3. Results of acute intervention for meeting uncomplicated criteria, performing an exercise treadmill test (ETT), and having a negative exercise test result. $\mathrm{MI}=$ myocardial infarction; $\mathrm{PTCA}=$ percutaneous transluminal coronary angioplasty. 
patients with AMI for early hospital discharge with its attendant savings in cost.

\section{References}

1. Torkelson LO. Rehabilitation of the patient with acute myocardial infarction. I Chronic Dis 1964;17:685-704.

2. Hamm LF, Stull GA, Crow RS. Exercise testing early after myocardial infarction; historic perspective and current uses. Prog Cardiovasc Dis 1986;28: 463-476.

3. Markiewicz W, Houston N, DeBusk RF, Exercise testing soon after myocardial infarction. Circulation 1977;56:26-31.

4. Theroux P, Waters DD, Halphen C, Debaisieux JC, Mizgala HF. Prognostic value of exercise testing soon after myocardial infarction. $N$ EngI I Med 1979;310:341-345.

5. Fuller CM, Raizner AE, Verani MS, Nahormek PA, Chahine RA, McEntree CW, Miller RR. Early post-myocardial infarction treadmill stress testing. Ann Intern Med 1981;94:734-739.

6. DeBusk RF, Haskell W. Symptom-limited versus heart-rate-limited exercise testing soon after myocardial infarction. Circulation 1980;61:738-743.

7. Starling MR, Crawford MH, Kennedy GT, O'Rourke RA. Treadmill exercise tests predischarge and six weeks post-myocardial infarction to detect abnormalities of known prognostic value. Ann Intern Med 1981;94:721-727. 8. O'Neill WW, Timmis G, Bourdillon P, Lai P, Ganghadarhan V, Walton J, Ramos R, Laufer N, Gordon S, Schork MA, Pitt B. A prospective randomized clinical trial of intracoronary streptokinase versus corvnury angiuplusty therapy of acute myocardial infarction. $N$ Engl J Med 1986;314:812-818.
9. Gruppo Italiano Per Lo Studio Della Steptochinasi Nell'Infarcto Miocardio (GISSI). Effective of intravenous thrombolytic treatment in acute myocardial infarction. Lancet 1986;1:397-401.

10. I.S.A.M. Study Group. A prospective trial of intravenous streptokinase in acute myocardial infarction. $N$ Engl I Med 1986;314:1465-1471.

11. Van der Laarse A, Vermeer F, Hermens WT, Willems GM, de Neef K, Simoons ML, Serruys PW, Res J, Verheugt FWA, Krauss XH, Bar F, de Zwaan $C$, Lubsen I. Effects of early intracoronary streptokinase on infarct size estimated from cumulative enzyme release and on enzyme release rate; a randomized trial of 533 patients with acute myocardial infarction. Am Heart $\}$ 1906;112:672-681.

12. Lown B, Vassaux C, Hood WB Jr, Fakhro AM, Kaplinksy E, Roberge G Unresolved problems in coronary care. Am I Cardiol 1967;20:494-503.

13. Holman BL, Hill TC, Wynne J, Lovett RD, Zimmerman RE, Smith EM. Single photon transaxial emission computed tomography of the heart in normal subjects and in patients with infarction. I Nucl Med 1979:20:736-745. 14. Simoons ML, Brand MV, de Zwaan C, Verheugt FWA, Remme WJ, Serruys PW, Bar F, Res ], Krauss XH, Vermeer R. Improved survival after early thrombolysis in acute myocardial infarction. Lancet 1985;2:578-582. 15. Leppo J, O'Brien J, Rothendler JA, Getchell JD, Lee VW. Dipyridamole thallium-210 scintigraphy in the prediction of future cardiac events after acute myocardial infarction. N Engl J Med 1984;310:1014-1018.

16. Pryor DB, Hindman MC, Wagner GS, Califf RM, Rhoads MK, Rosati RA Early discharge after acute myocardial infarction. Ann Intern Med 1983; 99:528-538.

17. Thibault GE, Mulley AG, Hutter AM Jr, Reder V, DeSanctis RW. Randomized trial of 7-day vs usual length of stuy for uncomplicaled myocardial infarction (abstr). Circulation 1985;72:suppl III:III-413. 